\title{
Corneal biomechanical properties in patients with Hashimoto's thyroiditis
}

\author{
Ahmet Kırgız ${ }^{1, A, C, D, F}$, Kübra Şerefoğlu Çabuk1, ${ }^{1, B}$, , Mikail Yetmis ${ }^{2, B}$, Kürşat Atalay ${ }^{1, C, E}$ \\ ${ }^{1}$ Department of Ophthalmology, Bağcllar Training and Research Hospital, Istanbul, Turkey \\ ${ }^{2}$ Department of Internal Medicine, Bağcılar Training and Research Hospital, Istanbul, Turkey \\ A - research concept and design; $B$ - collection and/or assembly of data; $C$ - data analysis and interpretation; \\ $D$ - writing the article; $E$ - critical revision of the article; $F$ - final approval of the article
}

\section{Ahmet Kırgız \\ E-mail: ahmetk1@yahoo.com \\ Funding sources \\ None declared \\ Conflict of interest \\ None declared}

Address for correspondence

Received on March 19, 2016

Reviewed on May 20, 2016

Accepted on February 5, 2018

Published online on October 12, 2018

\section{Cite as}

Kırgız A, Çabuk K, Yetmis M, Atalay K. Corneal biomechanical properties in patients with Hashimoto's thyroiditis. Adv Clin Exp Med. 2019;28(1):109-112. doi:10.17219/acem/85039

DOI

10.17219/acem/85039

\section{Copyright}

Copyright by Author(s)

This is an article distributed under the terms of the

Creative Commons Attribution Non-Commercial License

(http://creativecommons.org/licenses/by-nc-nd/4.0/)

\section{Abstract}

Background. Hashimoto's thyroiditis (HT) is an autoimmune endocrine disorder that results from a dysregulation of the immune system leading to an immune attack on the thyroid gland. It has potential effects on different organs and tissues.

Objectives. The aim of the study was to investigate the effect of HT on corneal biomechanical properties using the ocular response analyzer (ORA).

Material and methods. A total of 48 patients with HT and 49 healthy subjects were enrolled in the study. The mean age of the patients and healthy subjects was $42.33 \pm 11.96$ and $40.20 \pm 12.60$ years, respectively $(p=0.39)$. All of the subjects underwent a full ophthalmological examination, including visual acuity, corneal pachymetry with topography, biomicroscopy, and funduscopy. Corneal biomechanical properties, including corneal hysteresis (CH) and corneal resistance factor (CRF), Goldmann-correlated intraocular pressure (IOPg) and corneal compensated IOP (IOPCC) were measured with the ORA.

Results. Central corneal thickness (CCT) in the patient group and the control group were not significantly different $(p=0.65)$. Corneal hysteresis of the HT patients was significantly lower than that of the control group ( $p=0.005$ ). There were no statistically significant differences in CRF between the 2 groups ( $p=0.53)$. Goldmann-correlated IOP and IOPCc were higher in the HT patients, but only IOPCc showed a statistically significant difference $(p=0.001)$.

Conclusions. In conclusion, our data shows that $\mathrm{HT}$ affects corneal biomechanical properties by decreasing $\mathrm{CH}$. Thus, IOPcc measured with the ORA should be taken into account when determining accurate IOP values in patients with HT.

Key words: corneal hysteresis, corneal resistance factor, Hashimoto's thyroiditis, ocular response analyzer 


\section{Introduction}

Hashimoto's thyroiditis (HT) is a chronic inflammation of the thyroid gland. It is now considered the most common autoimmune disease, ${ }^{1,2}$ the most common endocrine disorder, ${ }^{3}$ as well as the most common cause of hypothyroidism. ${ }^{4}$ It affects predominantly women. It is characterized by elevated levels of antithyroglobulin (Anti-Tg) antibody and antithyroid peroxidase (anti-TPO), and a characteristic hypoechogenic pattern in ultrasonography of the thyroid gland. It has different clinical stages ranging from euthyroidism to hypothyroidism. ${ }^{5}$

There is a relationship between thyroid diseases and the eye: so-called thyroid eye disease (TED). It is most commonly associated with Graves' disease (GD) and is occasionally seen in the euthyroid state. ${ }^{6,7}$ The clinical manifestations include exophthalmos, conjunctival hyperemia and chemosis, soft tissue swelling, eyelid retraction, ophthalmoplegia, increases in orbital volume that may lead to increased intraorbital pressure, keratopathy, and optic neuropathy. ${ }^{8,9}$ In contrast, TED in HT is extremely uncommon and there are limited reports of it in the literature. ${ }^{10-12}$

Because of the fact that one of the most important manifestations of TED is corneal and ocular surface involvement, investigators have studied alterations in corneal biomechanical properties in TED patients. ${ }^{13,14}$ There are also some studies about corneal microstructural changes using corneal pachymetry and confocal biomicroscopy in GD. ${ }^{15,16}$ To the best of our knowledge, alterations in corneal biomechanical properties in patients with HT have not been studied in detail before.

The ocular response analyzer (ORA) (Reichert Ophthalmic Instruments, Buffalo, USA) was introduced with the aim of providing information on corneal biomechanical factors such as hysteresis and resistance. It determines noncontact intraocular pressure (IOP) as Goldmann-correlated IOP (IOPg) and corneal-compensated IOP (IOPcc). This modality has been designed to quantify IOP by integrating corneal biomechanical factors, allowing the practitioner to reduce the margin of error in IOP measurements as compared with the conventional method, Goldmann applanation tonometry (GAT) ${ }^{17}$

The aim of the study was to investigate the effect of HT disease on corneal biomechanical properties using the ORA.

\section{Material and methods}

Between June 2015 and January 2016, 51 patients diagnosed with HT at the Endocrinology Department of Bağcılar Training and Research Hospital, Istanbul, Turkey, were referred to our eye clinic. Out of these 51, 48 exclusively female patients were included in this prospective observational study (Group 1) to eliminate any errors that might depend on gender differences. For the control group (Group 2), 49 healthy female subjects who visited our outpatient general clinics for routine ocular checkups or for glasses prescriptions were matched regarding age. Whenever both eyes met the criteria, the right eye of each participant was included. Patients with a history of corneal surgery, ocular trauma, corneal scarring, or any concurrent ocular disease were excluded from the study, as were contact lens wearers and women who were pregnant or lactating during the course of the study. All the patients with HT were under treatment and none of the patients had TED. The study followed the tenets of the Declaration of Helsinki and was approved by the local ethics committee.

All the subjects underwent a full ophthalmological examination including visual acuity, biomicroscopy, funduscopy, corneal pachymetry by Sirius topographer (Costruzione Strumenti Oftalmici, Florence, Italy), measurement of corneal hysteresis $(\mathrm{CH})$ and corneal resistance factor (CRF), as well as IOPg and IOPcc using the ORA. All ORA measurements were obtained using the same calibrated instrument by the same masked technician. All the patients underwent measurements while sitting and were asked to fix their vision on a target light as the measurement was taken. A noncontact probe scanned the central corneal area and released an air puff. For each patient, 4 measurements with a minimum waveform score (WS) of 6.0 were obtained. ${ }^{18}$ The best signal value was used in the statistical evaluation.

All the statistical analyses were performed with SPSS for Windows v. 21.0 (SPSS Inc., Chicago, USA). The parameters used in the study were expressed as means \pm standard deviation (SD). The normality of the data was tested with the Kolmogorov-Smirnov test. Student's t-test was used to determine the significance of differences in the results. A p-value of less than 0.05 was considered statistically significant.

\section{Results}

The mean age of the patients was $42.33 \pm 11.96$ years (range: 17-62 years) in the group with HT (Group 1) and $40.20 \pm 12.60$ years (range: $17-61$ years) in the control group (Group 2) ( $\mathrm{p}=0.39)$. Central corneal thickness (CCT) values were not significantly different between the groups $(\mathrm{p}=0.65)$, as shown in Table 1 .

Corneal hysteresis of HT patients was significantly lower than that of the control group ( $\mathrm{p}=0.005)$. There was no statistically significant difference in CRF between the 2 groups ( $\mathrm{p}=0.53)$. Goldmann-correlated IOP and IOPcc were higher in the HT patients, but only IOPcc showed a statistically significant difference $(\mathrm{p}=0.001)$ (Table 1$)$.

\section{Discussion}

The structure and the properties of soft tissue, such as the cornea, are dependent on the biochemical and physical nature of the components present. Stress 
Table 1. The demographic and corneal biomechanical features of the study participants

\begin{tabular}{|l|c|c|c|}
\multicolumn{1}{|c|}{ Variable } & $\begin{array}{c}\text { Hashimoto's } \\
\text { thyroiditis }(\mathrm{n}=48)\end{array}$ & Control $(\mathrm{n}=49)$ & p-value \\
\hline Age [years] & $42.33 \pm 11.96$ & $40.2 \pm 12.6$ & 0.39 \\
\hline IOPg [mm Hg] & $16.73 \pm 3.52$ & $15.78 \pm 3.16$ & 0.16 \\
\hline IOPCC [mm Hg] & $17.89 \pm 3.19$ & $15.85 \pm 2.81$ & 0.001 \\
\hline CH [mm Hg] & $9.51 \pm 1.31$ & $10.27 \pm 1.28$ & 0.005 \\
\hline CRF [mm Hg] & $10.11 \pm 1.66$ & $10.31 \pm 1.54$ & 0.53 \\
\hline CCT [ $\mu \mathrm{mm}]$ & $541.83 \pm 30.54$ & $544.75 \pm 33.63$ & 0.65 \\
\hline
\end{tabular}

IOP - intraocular pressure; IOPg - Goldmann-correlated IOP;

IOPCC - corneal-compensated IOP; $\mathrm{CH}$ - corneal hysteresis;

CRF - corneal resistance factor; CCT - central corneal thickness.

to these components and their response to it show the biomechanical properties of the tissue. The ORA is a noncontact tonometer that uses a rapid air pulse to create stress on the cornea and an electro-optical system to record the corneal deformation. ${ }^{17}$ In our study, we wanted to evaluate the effect of HT on corneal biomechanical properties measured with the ORA, and we found that the $\mathrm{CH}$ of $\mathrm{HT}$ patients was significantly lower than that of the healthy control group.

Corneal hysteresis is a quantification of the ability of the cornea to absorb and/or dissipate energy: so-called viscous dampening. Low values of $\mathrm{CH}$ indicate a floppy cornea and less corneal viscous dampening, which may be explained by an alteration in the corneal structure. There are some reports that show a decrease of $\mathrm{CH}$ in diseases that cause alterations in corneal structure, such as keratoconus $^{19,20}$ and myopic eyes, ${ }^{21}$ in eyes of patients with diabetes mellitus, ${ }^{22}$ in post-laser in situ keratomileusis eyes, ${ }^{23}$ and in eyes that have undergone penetrating keratoplasty. ${ }^{24}$ However, these alterations in corneal structure are also found in some systemic diseases, such as systemic lupus erythematosus, ${ }^{25}$ rheumatoid arthritis, ${ }^{26}$ Marfan syndrome, ${ }^{27}$ and other inflammatory conditions. The corneas of patients with HT may have similar alterations in the corneal microstructure known to occur in these corneal diseases.

An eye with low $\mathrm{CH}$ has a lower ability to absorb energy; in the presence of high IOP, the cornea cannot absorb energy, and all the pressure is exerted on the optic nerve and peripapillary tissues. ${ }^{28}$ Thus, low $\mathrm{CH}$ is associated with high IOP in both glaucoma patients and healthy individuals, and it may be a risk factor for the progression of glaucoma. In our study, we also found that the IOPcc of HT patients was higher compared with the control group. It is known that the IOPcc is not affected by CCT when measured using the ORA, which might provide a better estimate of the real IOP value than GAT measurements do. Routine IOP measurements using GAT may underestimate IOP in HT patients, so this point should be kept in mind when examining eyes with suspicious cupping and borderline IOP.
In this study, we found no statistically significant difference between the HT patients and the control group regarding CRF. In fact, CRF is mainly determined by the elastic properties of the cornea and is a parameter more closely associated with CCT than $\mathrm{CH} .{ }^{29}$ Because CCT measurements showed no statistical differences between the HT patients and the healthy subjects, it was consistent that CRF did not differ between the 2 groups.

There are some reports investigating the biomechanical properties of the cornea in patients with GD with or without TED. Karabulut et al. evaluated corneal biomechanical properties in patients with TED using the ORA and found significant decreases in $\mathrm{CH}$ but no significant differences in CRF and CCT. ${ }^{13}$ They also reported higher IOPg and IOPcc levels among TED patients compared with the control group. Moghimi et al. evaluated TED patients and reported the same findings as in the previous study. ${ }^{14}$ These findings and our study results suggest that there is a strong relation between the autoimmune thyroid diseases - HT and GD. The etiology of HT and GD involves common pathways in which thyroid-reactive T cells escape tolerance and infiltrate the thyroid, and unique pathways in which these thyroid-reactive $\mathrm{T}$ cells either cause thyroid cell death (in HT) or stimulation (in GD). ${ }^{30}$ Thus, it is not surprising that both autoimmune thyroid diseases have similar effects on corneal biomechanical properties. Further studies are warranted to define which inflammatory process in the corneal tissue of these patients is responsible for this biomechanical change.

Some limitations of this study should be mentioned. Firstly, since this is a cross-sectional study, a direct cause and effect cannot be determined. Secondly, the exact mechanisms causing abovementioned alterations should be studied in detail with genetic and specular microscopic evaluation as well. Finally, the small sample size restricted our ability to make generalized conclusions.

\section{Conclusions}

In conclusion, our data shows that $\mathrm{HT}$ affects corneal biomechanical properties by decreasing $\mathrm{CH}$. Thus, IOPcc measured with the ORA should be taken into account when determining the accurate IOP value in patients with HT.

\section{References}

1. Jacobson DL, Gange SJ, Rose NR, Graham NM. Epidemiology and estimated population burden of selected autoimmune diseases in the United States. Clin Immunol Immunopathol. 1997;84(3):223-243.

2. McLeod DS, Cooper DS. The incidence and prevalence of thyroid autoimmunity. Endocrine. 2012;42(2):252-265.

3. Golden SH, Robinson KA, Saldanha I, Anton B, Ladenson PW. Clinical review. Prevalence and incidence of endocrine and metabolic disorders in the United States: A comprehensive review. J Clin Endocrinol Metab. 2009;94(6):1853-1878.

4. Vanderpump MP. The epidemiology of thyroid disease. Br Med Bull. 2011;99:39-51.

5. Pearce EN, Farwell AP, Braverman LE. Thyroiditis. N Engl J Med. 2003;348(26):2646-2655. 
6. Jacobson DM. Dysthyroid orbitopathy. Sem Neurol. 2000;20(1):43-54.

7. El-Kaissi S, Frauman AG, Wall JR. Thyroid-associated ophthalmopathy: A practical guide to classification, natural history and management. Intern Med J. 2004;34(8):482-491.

8. Bartley GB, Fatourechi V, Kadrmas EF, et al. Clinical features of Graves' ophthalmopathy in an incidence cohort. Am J Ophthalmol. 1996;121(3):284-290.

9. Garrity JA, Bahn RS. Pathogenesis of Graves ophthalmopathy: Implications for prediction, prevention and treatment. Am J Ophthalmol. 2006;142(1):147-153.

10. Grzesiuk W, Szydlarska D, Pragacz A, Bar-Andziak E. Thyroid-associated orbitopathy in patients with Hashimoto's thyroiditis: A case report. Pol Arch Med Wewn. 2008;118(5):318-321.

11. Hiraga A, Mimura M, Kamitsukasa l. Isolated inferior rectus muscle myopathy due to Hashimoto's thyroiditis. Intern Med. 2008;47(13):1283-1284.

12. Kan E, Kan EK, Ecemis G, Colak R. Presence of thyroid-associated ophthalmopathy in Hashimoto's thyroiditis. Int J Ophthalmol. 2014;7(4):644-647.

13. Karabulut GO, Kaynak P, Altan C, et al. Corneal biomechanical properties in thyroid eye disease. Kaohsiung J Med Sci. 2014;30(6):299-304.

14. Moghimi S, Safizadeh M, Mazloumi M, Hosseini H, Vahedian Z, Rajabi MT. Evaluation of corneal biomechanical properties in patients with thyroid eye disease using ocular response analyzer. J Glaucoma. 2016;25(3):269-273

15. Konuk O, Aktas Z, Aksoy S, Onol M, Unal M. Hyperthyroidism and severity of orbital disease do not change the central corneal thickness in Graves' ophthalmopathy. Eur J Ophthalmol. 2008;18(1):125-127.

16. Villani E, Viola F, Sala R, et al. Corneal involvement in Graves' orbitopathy: An in vivo confocal study. Invest Ophthalmol Vis Sci. 2010;51(9):4574-4578.

17. Luce DA. Determining in vivo biomechanical properties of the cornea with an ocular response analyzer. I Cataract Refract Surg. 2005;31(1):156-162.

18. Mandalos A, Anastasopoulos E, Makris L, Dervenis N, Kilintzis V, Topouzis $F$. Inter-examiner reproducibility of ocular response analyzer using the waveform score quality index in healthy subjects. J Glaucoma. 2013;22(2):152-155.
19. Shah S, Laiquzzaman M, Bhojwani R, Mantry S, Cunliffe I. Assessment of the biomechanical properties of the cornea with ocular response analyzer in normal and keratoconic eyes. Invest Ophthalmol Vis Sci. 2007;48(7):3026-3031.

20. Fontes BM, Junior RA, Jardim D, Velarde GC, Nose W. Ability of corneal biomechanical metrics and anterior segment data in the differentiation of keratoconus and healthy corneas. Ophthalmology. 2010;117(4):673-679.

21. Altan C, Demirel B, Azman E, et al. Biomechanical properties of axially myopic cornea. Eur J Ophthalmol. 2012;22(Suppl 7):S24-28.

22. Goldich Y, Barkana Y, Gerber Y, et al. Effect of diabetes mellitus on biomechanical parameters of the cornea. J Cataract Refract Surg. 2009;35(4):715-719.

23. Ortiz D, Piñero D, Shabayek MH, Arnalich-Montiel F, Alió JL. Corneal biomechanical properties in normal, post-laser in situ keratomileusis, and keratoconic eyes. J Cataract Refract Surg. 2007;33(8):1371-1375.

24. Shin JY, Choi JS, Oh JY, Kim MK, Lee JH, Wee WR. Evaluation of corneal biomechanical properties following penetrating keratoplasty using the ocular response analyzer. Korean J Ophthalmol. 2010;24(3):139-142.

25. Yazici AT, Kara N, Yüksel K, et al. The biomechanical properties of the cornea in patients with systemic lupus erythematosus. Eye (Lond). 2011;25(8):1005-1009.

26. Can ME, Erten S, Can GD, Cakmak HB, Sarac O, Cagil N. Corneal biomechanical properties in rheumatoid arthritis. Eye Contact Lens. 2015;41(6):382-385

27. Kara N, Bozkurt E, Baz O, et al. Corneal biomechanical properties and intraocular pressure measurement in Marfan patients. J Cataract Refract Surg. 2012;38(2):309-314.

28. Congdon NG, Broman MA, Bandeen-Roche K, Grover D, Quigley HA. Central corneal thickness and hysteresis associated with glaucoma damage. Am J Ophthalmol. 2006;141(5):868-875.

29. Shah S, Laiquzzaman M, Cunliffe I, Mantry S. The use of the Reichert ocular response analyzer to establish the relationship between ocular hysteresis, corneal resistance factor and central corneal thickness in normal eyes. Cont Lens Anterior Eye. 2006;29(5):257-262.

30. Tomer Y. Genetic susceptibility to autoimmune thyroid disease: Past, present and future. Thyroid. 2010;20(7):715-725. 